\title{
IMPROVING STUDENT ASSESSMENT FEEDBACK IN AN INTRODUCTORY ACCOUNTING COURSE THROUGH TWO-STAGE COOPERATIVE ASSESSMENT
}

\section{S. J. Kruger}

School of Accountancy

Stellenbosch University

Stellenbosch, South Africa

e-mail: sjkruger@sun.ac.za

\section{ABSTRACT}

Student feedback is an important part of the formative assessment process. Previous research shows that there is room for improvement in student feedback on accounting education. Various benefits, especially those associated with the development of certain pervasive skills through group learning, have been established through research. The two-stage group examination offers students the opportunity to become active participants in the feedback process, while harvesting the benefits of teamwork. This study involving 24 students enrolled for an introductory accounting course evaluated the efficacy of the two-stage examination as an intervention to improve feedback.

Students perceived that examination retakes in a team environment were helpful to establish where they made mistakes and showed them how they could improve their future performance. They could further establish how they performed compared to their peers. The examination retakes also helped to improve their understanding of the work and how they could improve their learning.

The intervention was well received by students despite reports of free riding. This study adds to the limited body of research on two-stage exams in accounting education.

Keywords: two-stage assessment, formative assessment, co-operative learning, accounting education, group assessment, peer learning

\section{INTRODUCTION}

Effective teaching, in the view of Lubbe (2014), requires "the creation of effective learning experiences, which are critical to achieving the values of a learned profession". As assessment drives student learning, it is important that assessment is constructively aligned with teaching and that it requires students to be active learners (Biggs 1999; Perera, Nguyen and Watty 2014). Effective feedback is an important component of formative assessment (Gibbs and Simpson 2005) and is an area in accounting education that generally needs improvement (Watty et al. 2013; Perera et al. 2014). Hattie and Timperley (2017) emphasise that more quantitative and 
qualitative research is needed on the effect of feedback in the learning process. Furthermore, to ensure an effective learning environment, accounting educators should consider not only content but also the method of lecturing (Clinton and Kohlmeyer III 2005). The Accounting Education Change Commission, have urged accounting educators to move away from the conventional lecturing approach. The historic approach to lecturing involves students as passive learners. Instead, methodologies that involve students as active participants in the learning process should be encouraged (Hwang et al. 2005). One such methodology is teamwork (Bay and Pacharn 2017). The South African Institute of Chartered Accountants (SAICA) highlights the ability to work in teams as an important pervasive skill in its competency framework (SAICA 2016).

Thus, SAICA has aligned its educational standards with those of the International Federation of Accountants (IFAC) by requiring that accounting academics ensure that technical competencies as well as specified pervasive skills are developed (Strauss-Keevy 2014). The use of team learning in accounting education can help to develop this pervasive skill (Opdecam et al. 2012; Keevy 2015).

Accounting educators should search for techniques to make cooperative learning more beneficial to students (Bay and Pacharn 2017). In attempting to develop one such technique, an intervention was designed to improve the feedback process and at the same time utilise the benefits of cooperative learning. This was done by implementing a two-stage assessment where students were required to re-do an assessment in small groups one day after they wrote the assessments individually. Students could improve their individual marks as the group assessment comprised 20 per cent of the mark, while their individual mark comprised 80 per cent of their final mark for the assessment. This type of intervention is referred to as a twostage cooperative test or assessment retake.

Only two studies involving assessment retakes in accounting education could be found. Hite (1996) found that performance of taxation students exposed to assessment retakes in taxation improved, while Gabbin and Wood (2008) found no significant improvement in the performance of students in an intermediate accounting II course. Bay and Pacharn (2017) argue that the inconsistent results on group assessment in accounting studies are a concern and that more research is required to find more effective techniques.

\section{RESEARCH PROBLEM}

The research problem identified is whether the retake of an assessment which involves cooperative learning is effective as a means of providing feedback to accounting students. 


\section{RESEARCH OBJECTIVES}

The first objective of the study was to determine the perceptions of students on how effective the group assessment retakes were in providing feedback. While many studies on cooperative learning have focused on the effect on performance, it is important to consider how satisfied students are with the learning environment (Opdecam and Everaert 2012; Reinig, Horowitz and Whittenburg 2014). Therefore, the second objective of the study was to determine how well the group tests were received by students.

\section{RESEARCH METHODOLOGY}

Students in the study were enrolled for an introductory accounting course. The final mark of students consisted of a predicate mark which counted 50 per cent of the final mark and a final assessment counting 50 per cent of the final mark. The predicate mark was made up of two extensive tests and six smaller tests. The two extensive tests contributed 50 per cent of the predicate mark, while the smaller tests counted for the remainder of the predicate mark. The intervention was applied to three of the smaller tests. For these tests the individual effort contributed 80 per cent of the mark, while the group effort contributed 20 per cent of the test mark for a specific student.

After completion of two group assessments, students were asked to complete questionnaires to gauge their perceptions regarding the research questions, which are listed in the next section. A mixed-methods approach, as advocated by Johnson and Onwuegbuzie (2004), was followed, which consisted of a quantitative analysis of the Likert-scale responses of students and a qualitative analysis of the open-ended questions.

\section{RESEARCH QUESTIONS}

To determine whether the group assessment retakes contributed to providing effective feedback to students, the following research questions were posed:

- $\quad$ Did the group test help students to determine where they made mistakes?

- Did the group test help students to determine their relative performance and how to improve their future performance?

- Did the group test help students to understand the work better?

- $\quad$ Did the group test help students to improve their way of learning?

A study of literature on students' feedback and cooperative learning informed the decision to conduct an empirical study, by means of a questionnaire. 


\section{LITERATURE STUDY}

\section{Formative assessment and feedback}

Assessment can be classified as diagnostic, summative or formative. Diagnostic assessment identifies abilities of students beforehand. Summative assessment grades students for the purpose of certification, which assists with the decision whether students may progress or not. The formative function of assessment is to provide feedback during learning. Owing to its value in the learning process, formative assessment is promoted as the preferred approach in assessment literature (Perera et al. 2014). Despite only a few studies having been done on formative assessment in accounting education (Curtis 2011), a significant body of literature established that formative assessment enhances student learning (Van Gennip, Segers and Tillema 2009).

A classroom climate where learning is more important than grading is ultimately more productive. The main purpose of assessment should be to improve the quality of teaching and learning, with feedback being a key strategy in formative assessment (Fluckiger et al. 2010). Hattie and Timperley (2017) define feedback as "information provided by an agent (e.g., teacher, peer, book, parent, experience) regarding aspects of one's performance or understanding".

Effective feedback needs to build on initial learning, can be a powerful influence on learning (Hattie and Timperley 2017) and is pivotal to ensuring the efficacy of formative assessment (Curtis 2011). However, resource constraints have led to a decline in formative assessment with a corresponding reduction in the quality and quantity of feedback (Gibbs and Simpson 2005). A consequence of resource constraints for accounting educators is large classes and a corresponding low lecturer/student ratio (De Lange and Watty 2011; Opdecam and Everaert 2012; Guthrie and Parker 2014; Guthrie, Evans and Burritt 2014; Samkin and Schneider 2014). These factors impact negatively on the ability of lecturers to provide individualised and timeous feedback to students (Watty et al. 2013; Pitt and Norton 2017). Accounting educators must find ways to improve formative assessment in the context of this challenge (Hesketh 2011). This was confirmed in a survey done among Australian accountancy students which found that approximately 30 per cent of students indicated that adequate feedback is not given. This dissatisfaction with feedback seems to occur in many universities throughout the world (Watty et al. 2013).

Notwithstanding this, lecturers' perceptions are that students are only interested in final grades; that they seem uninterested in written feedback by not collecting test papers; and they 
have a general lack of interest in their studies. This could have contributed to the fact that lecturers do not put sufficient effort into the feedback process (Watty et al. 2013; Pitt and Norton 2017). Weaver (2006) argued that students would value feedback more if academics put more effort into providing better feedback. It is therefore important that lecturers equip themselves to provide effective feedback. Designing formative assessment with the corresponding feedback must preferably be done in a way which creates an environment where students are encouraged to participate actively. Ultimately, what the students do is paramount to their success (Biggs 1999). Involving students as active partners in the assessment process enhances the teaching and learning process (Fluckiger et al. 2010).

In a general sense, Evans (2013) contended that learner needs, task purpose and the learning environment should impact on the chosen feedback methodology, while Weaver (2006) stated that "[t]utors can ensure that their feedback is constructive and clearly set in the context of learning outcomes and assessment criteria, which guides the students on how to improve their performance".

Feedback has various components and can happen in various ways. One aspect is to help students to establish a concept of quality that is in line with that of the lecturer. Model answers on previous assessment questions can be valuable to achieve this (Hounsell et al. 2008). In an essay-style assessment setting, Ellery (2008) found that after providing feedback after a test, and giving students a second opportunity based on the same content to be studied, the quality of the work of students improved.

In other studies on feedback, McCarthy (2015) used written, audio and video feedback and concluded that feedback is not a "one size fits all" approach and should be tailor-made depending on the type of subject and the type of assessment. Some interventions in accounting education have been documented and include a study which concluded that accounting students found the use of screencast technology helpful as feedback on assessments. This included audio and visual material being made available to students after the assessment (Marriott and Teoh 2012). Blayney and Freeman (2008) developed a spreadsheet-driven method to provide immediate feedback to accounting students in a formative assessment setting, using "drill-andpractice questions". When feedback is given by making use of two-stage group assessments, it is worth considering the body of research on cooperative learning.

\section{Cooperative learning}

According to Hite (1996), cooperative learning is generally defined as "a small group of heterogeneous students who work together to help each other learn".

Quite a number of studies in accounting education have been done on group work with a 
strong focus on the development of pervasive skills, mainly the ability to work in a team (Stainbank 2003; 2009; Rudman and Kruger 2014; Smit and Steenkamp 2015) and the development of communication and time management skills (Bay and Pacharn 2017). The combined benefits of group learning may contribute to produce professional accountants who are life-long learners, self-sufficient workers and critical thinkers (Cortright et al. 2003).

To evaluate the success of cooperative learning an important aspect researched was the improvement in the performance of students as far as achieving better grades were concerned. In accounting education results in respect of improvement in performance due to cooperative learning have been mixed and team learning interventions have also not been as effective as in some other disciplines (Clinton and Kohlmeyer III 2005; Bay and Pacharn 2017). When Gabbin and Wood (2008) analysed literature on cooperative learning in accounting education, they found that only three of the 16 studies reported a significant improvement in performance. Only one of these studies (Hite 1996) was an assessment retake, also referred to as a two-stage cooperative assessment or "pyramid" examination (Zipp 2007).

Where improvements in performance were found, they could have been due to the testing effect (Roediger and Karpicke 2006) and the effect of working in a group may not have been the cause of improved performance. Hite (1996), however, argued that if students misread a question, they would probably misread it again in an individual effort, and misunderstood concepts would lead to repeated errors. In these instances, the input from other students could potentially improve understanding and interpretation.

In other disciplines, researchers reported improved individual retention using two-stage group assessment, namely in a sports psychology course (Cortright et al. 2003) and in sociology (Zipp 2007). In the two studies involving assessment retakes in accounting education it was found that performance of taxation students improved (Hite 1996), while Gabbin and Wood (2008) found no significant improvement in the performance of students in an intermediate accounting II course.

\section{THE RETAKE OF AN ASSESSMENT INVOLVING COOPERATIVE LEARNING}

The allocation of a mark for graded assessment can be seen as summative and formative (Perera et al. 2014). Many students are driven mainly by the achievement of grades and would therefore prioritise summative assessment (Watty et al. 2013). The fact that the mark achieved in the group exam forms part of the student's performance mark for the semester should therefore motivate students to perform well. An examination retake is however primarily formative assessment as it has the aim to improve learning through peer-feedback.

While lecturers often try to facilitate discussions and participation in conventional 
lectures, it is usually only a small portion of students who contribute to the discussions. Ideally students must not be passive recipients of information but should actively participate (Hite 1996). A hallmark of successful team learning is that students assume the role of both teacher and learner (Cottell and Millis 1992). It has been documented in research that explaining concepts to others, i.e. taking on the role of a teacher, provides cognitive benefits (Bargh and Schul 1980; Slavin and Karweit 1981). In a group learning environment, questions asked by group members also contribute significantly to the learning process (Shaw et al. 1979; Shaw and Small 1981).

Another aspect that can contribute to the success of cooperative learning is that students might put in more effort. Knowing that they will be part of a team and be expected to contribute can motivate them to be better prepared for group work (Hite 1996; Zipp 2007). To utilise the benefits of team learning, the students in this study were required to complete the re-take of the test during the next class session in groups of three. Students were not notified that this would happen and therefore did not specifically prepare for the group test.

The effectiveness of the conventional way of providing feedback, namely to provide model answers in order to give students the opportunity to compare their answers to it to determine where they have erred, can be questioned as many accounting students -40 per cent or more - do not even pick up their marked scripts after assessments. This perceived lack of interest among students after the completion of assessment has also been reported at Australian universities (Watty et al. 2013). In this intervention the students had an incentive to participate actively in the feedback process as they could improve their marks obtained in the individual tests. Watty et al. (2013) found that students prefer feedback that is timeous, detailed, individualised and constructive.

The solution was handed out to the groups after one answer per group was collected by the lecturer for grading the group effort. The students were then given the opportunity to compare their answers with the suggested solution and to clarify issues with the lecturer.

This process meant that the feedback process was completed within 24 hours, which satisfied the requirement that feedback should be provided timeously. There was also the opportunity for peers to provide detailed, individualised and constructive input to fellow students in the small group environment.

Hite (1996) argues that a two-stage group exam is a cooperative learning technique citing the five elements Johnson et al. (1991) (as in Hite (1996) and Gabin and Wood (2008)) consider as requirements namely positive interdependence, face-to-face interaction, individual accountability, collaborative skills and group processing. In this particular study where the mark for the group exam counted 20 per cent of the final exam mark, it was in student's interest 
to employ their skills to achieve a common goal of a good exam mark, thereby encouraging positive interdependence. Group processing happened through face-to-face interaction where they compared their answer to the suggested solution (Gabbin and Wood 2008). Students were individually accountable in the process as the individual component of the examination counted 80 per cent towards the final examination mark. The two-stage group exam in this study is therefore considered to be a cooperative learning technique.

\section{QUESTIONNAIRE DESIGN, DATA COLLECTION, DATA ANALYSIS AND SUBJECTS}

\section{Questionnaire design and data collection}

To answer the research questions, eight statements were formulated to test the constructs of identification of mistakes (construct a), improved performance (construct b), improvement in understanding (construct c) and improved way of learning (construct d). The actual questions posed to the students with the respective mean responses are presented in Table 1. The ranking of the four constructs based on the student responses is presented in Table 2.

The following open-ended questions were also formulated to gain an understanding of how effective the group assessment was in providing better feedback:

a) Did the group tests support your learning? Explain your answer.

b) Did the group test improve your marks? Why or why not?

To gain an understanding as to how satisfied students were with the group tests, as well as to identify issues for future improvement, the following open-ended research questions were formulated:

c) Would the fact that the group component counted 20 per cent of the total test mark lead to your learning less for individual tests in future, and did this provide enough incentive for you to do well in the group component?

d) Would you want to make use of group tests again in the future? Yes/no and why?

e) What are the advantages of a group test? Explain.

f) I enjoyed the group tests because ...

g) What are the disadvantages of a group test? Explain.

h) I did not enjoy the group tests because ... 
The questionnaires were completed during class time and the data were captured on a spreadsheet, after which they were analysed by a statistician.

\section{Data analysis}

The means and standard deviations for each of the Likert-scale questions were calculated and are presented in Table 1. The Cronbach Alphas of the questions testing the same constructs were calculated and were found to prove sufficient reliability. A mixed model ANOVA was used to analyse the combined constructs. A one way ANOVA was used to determine any statistical differences between the responses of male and female students. The p-values calculated are presented in Table 1.

The answers to the open-ended questions were analysed to identify common themes after which the occurrence of common themes was quantified. Typical answers from students are reported under the qualitative analysis section of this article.

\section{Subjects (students)}

Findings on the successful implementation of cooperative learning can differ between countries owing to different educational and social systems (Hwang et al. 2005). In a South African context the "increasingly changing cultural landscape of student populations" need to be considered in group learning settings (Thondhlana and Belluigi 2014). Apartheid has led to "systemic economic inequities, with the legacy of a shortage of teachers, poorly trained teachers, overcrowded classrooms, a perpetual lack of funding, lack of support programs, weak parent-teacher bodies, and little community support". This has led to a situation where educational opportunities are limited for African, Coloured and to a lesser extent Indian learners (collectively referred to as "black" learners), (Coetzee, Schmulian and Kotze 2014). Even though apartheid was abandoned in 1994 many people still carry the scars and inferiority complexes caused by the discrimination against black communities (Thondhlana and Belluigi 2016). The fragmented South African education system often leads to especially black students being unprepared for higher education resulting in less favourable outcomes for these students (Cross and Carpentier 2009). At school level it was found that many of these learners engaged in rote learning and often did not acquire the skill to learn independently. It is therefore important that learning opportunities are created to increase the chance of success for these students (Mungal and Cloete 2017).

The students who participated in the study were enrolled in a university access programme at a university in the Western Cape. They were the only students on the programme who took introductory accounting as a subject and all of them participated in the study. Twenty-two 
students were coloured while two of the students were African. They came from disadvantaged educational backgrounds, but had the potential to be successful in a higher education setting. Fourteen of the students were female and 10 were male.

\section{RESULTS}

Table 1: Likert Scale question responses

\begin{tabular}{|c|c|c|c|c|c|c|c|c|}
\hline Statement & Mean & $\begin{array}{l}\text { Std } \\
\text { dev }\end{array}$ & Female & $\begin{array}{l}\text { Std } \\
\text { dev }\end{array}$ & Male & $\begin{array}{l}\text { Std } \\
\text { dev }\end{array}$ & p & C \\
\hline $\begin{array}{l}\text { 1. Discussions during group tests helped } \\
\text { me understand where I am making my } \\
\text { mistakes. }\end{array}$ & 4.29 & 1.23 & 4.71 & 0.73 & 3.70 & 1.57 & 0.04 & a \\
\hline $\begin{array}{l}\text { 2. Once I have done the group test I } \\
\text { understand what I did wrong in my } \\
\text { individual test. }\end{array}$ & 4.29 & 1.20 & 4.50 & 0.65 & 4.00 & 1.70 & 0.32 & a \\
\hline $\begin{array}{l}\text { 3. The group test shows me how to do } \\
\text { better next time. }\end{array}$ & 4.17 & 1.01 & 4.29 & 0.83 & 4.00 & 1.25 & 0.39 & $b$ \\
\hline $\begin{array}{l}\text { 4. When we do group tests it gives me an } \\
\text { idea of how well I am doing in relation to } \\
\text { fellow students. }\end{array}$ & 4.08 & 0.88 & 4.00 & 0.88 & 4.20 & 0.92 & 0.59 & $b$ \\
\hline $\begin{array}{l}\text { 5. The group test helps me to understand } \\
\text { the work better. }\end{array}$ & 3.88 & 0.95 & 4.00 & 0.68 & 3.70 & 1.25 & 0.46 & C \\
\hline $\begin{array}{l}\text { 6. The discussions during the group tests } \\
\text { helped me to clarify things I hadn't fully } \\
\text { understood. }\end{array}$ & 3.83 & 0.96 & 3.93 & 0.83 & 3.70 & 1.16 & 0.58 & c \\
\hline $\begin{array}{l}\text { 7. Discussions during group tests helped } \\
\text { me understand how well I was learning } \\
\text { and how I might improve. }\end{array}$ & 3.71 & 1.27 & 3.93 & 1.07 & 3.40 & 1.51 & 0.33 & $d$ \\
\hline $\begin{array}{l}\text { 8. Discussions during group tests helped } \\
\text { me to improve my ways of learning and } \\
\text { studying for this subject. }\end{array}$ & 3.75 & 1.11 & 3.71 & 1.14 & 3.80 & 1.14 & 0.86 & $d$ \\
\hline
\end{tabular}

The statements above are presented in order of mean scores from high to low. In the actual questionnaire presented to students the questions were in random order with the respective constructs (indicated in the column labelled "C") in different positions.

A mixed model ANOVA was used to analyse the combined constructs (as indicated in the column labelled "C" in Table 1).

Table 2: Construct comparison

\begin{tabular}{|c|l|c|c|}
\hline Construct & Level of factor & Mean & $\begin{array}{c}\text { Standard } \\
\text { Deviation }\end{array}$ \\
\hline a & Identifying mistakes & $4.29^{\mathrm{a}}$ & 1.14 \\
\hline $\mathrm{b}$ & Improved performance & $4.13^{\mathrm{ab}}$ & 0.77 \\
\hline $\mathrm{c}$ & Improved understanding & $3.85^{\mathrm{bc}}$ & 0.91 \\
\hline $\mathrm{d}$ & Learning & $3.73^{\mathrm{c}}$ & 1.09 \\
\hline
\end{tabular}

Constructs with the same superscript are not substantially different.

In Table 2, the constructs of identifying mistakes and improved performance were ranked 
higher by students than improvement in understanding and learning, while improved performance and improved understanding were ranked substantially the same by students.

\section{Qualitative analysis}

The results of the open-ended questions were as follows:

\section{a. Did the group tests support your learning? Explain your answer.}

Seventeen students answered "yes" and six answered "no".

Positive comments:

"It helped me to understand some things I didn't understand before the group test." (10 similar responses).

"Some members in the group explain the work in a much simpler and understanding way." (seven similar responses on experiencing the benefit of group members explaining the work to each other).

"It did improve my learning a lot, because you give your opinion and the explanation of the work helps you."

"Everyone gave comments that improved my thoughts on how I saw a question."

"Instead of memorising work, I got the opportunity to voice my opinion."

Negative comments:

"No, I wasn't challenged when I gave an answer."

"Not really, I have already performed well in Accounting."

\section{b. Did the group test improve your marks? Why or why not?}

Eighteen students answered "yes" and four "no", with one being undecided.

The comments on improvement mostly referred to better understanding and correction of mistakes made by group members during the individual tests.

"Yes, some of the things I didn't know my group members knew."

"Yes, stuff I did not understand became understandable."

"Yes, it improved my mark, because there were a few topics my group members explained to me that I did not understand."

A noteworthy comment was made by one of the students who indicated "No":

"No, other students seemed to persuade me that my way was wrong, but it wasn't." 
The fact that students could submit only one answer per group seems to have led to a situation where, in some cases, students who had the right answer got outvoted by the group. This was also found by researchers who suggested that a solution could be to allow students to hand in their own answers after the group effort (Zipp 2007).

\section{c. Do you think that you would learn less for future tests if a group test will contribute 20 per cent of your mark? Explain your answer.}

Only one of the 23 respondents indicated that he/she will learn less because of the group test. Some of the comments:

"No. It's my individual mark that would satisfy me the most. One group test is an opportunity to improve."

"No, $20 \%$ is a low percentage so I still would want to do very well in my individual test."

"No, because you don't know if your group is going to get a good mark and you have to study to do well in your individual test."

\section{d. Would you want to make use of group tests again in the future? Yes/no and why?}

Twenty-one students answered "yes" and two answered "no".

Positive:

"I always see improvements after a group test."

"Not only does it improve my marks but it helps me to better understand this subject."

Of all the positive comments, seven related to improved understanding, four to an improvement in marks and five to a combination of improvement in marks and better understanding. Other comments had a strong reference to the value added by group members:

"It sometimes helps me to see how others see things."

"I can learn from others and see where I went wrong." (two similar comments)

"It gives me a chance to see how other students in my class understand the subject."

Negative:

"I don’t always work well in groups. I work better on my own." 


\section{e. What are the advantages of a group test? Explain.}

"You can better your marks, learn more, as well as understand the work better than before."

"Better understanding of the work, more heads, more facts."

"It helps you moderate yourself and improve your own knowledge, because other people may know things that you don't know. That is when you start learning."

"We as students have the opportunity to not only hear from the lecturer but also from one another. We can also see how other students view topics."

The main advantages of the group test, according to the students, were the improvement of marks (14 mentions), improving understanding (nine mentions) and the benefit of learning from team members (six mentions).

\section{f. I enjoyed the group tests because ...}

Three students did not respond, and one indicated that she did not enjoy the group test. Eleven students gave comments in line with improved understanding, with seven indicating that they enjoyed the opportunity to corroborate with fellow students. Some of the remarks were:

"It's a good experience to know how others do their work."

"It helped me moderate myself, how well I understand the work and where I must improve on."

"I learned from it and it improved my mark."

"It's a fun and social way to learn."

"I like to share ideas with others."

\section{g. What are the disadvantages of a group test? Explain.}

"I think being in a group with people who don't want to work, doesn't participate and just wait for the answers." (12 similar mentions referring to the "free rider" problem)

"Arguments might occur, students might be misled and end up leaving the class being more confused." (five mentions referring to getting confused)

"When the group disagrees on an answer and if some people don't contribute." (three other mentions of disagreement)

"One person sometimes dominates the group, because the others are not as good as him/her."

"Group members who don't want to communicate because of language differences."

\section{h. I did not enjoy the group tests because ...}

"Sometimes you don't learn anything."

"My other group members didn't want to speak English and I don't understand Afrikaans, so it wasn't good because she does know English and she also understands it." 
"I was writing it for the second time."

"It took a bit too long, too many debating who is right and what to do."

"There were language problems and not all group members participated."

"I had a member in my group who didn't want to contribute, he just copied our work." (six similar responses referring to free riders)

"Lack of good communication, not agreeing on answers."

"We were all uncertain about the answers."

"We did not communicate a lot."

\section{DISCUSSION}

\section{Learning from mistakes}

Identifying mistakes and knowing why mistakes were made is seen as an important benefit of effective feedback and is usually measured by researchers when researching student feedback (Gilbert, Whitelock and Gale 2011; Marriott and Teoh 2012). In the present study, the mean for both statements ( 1 and 2 ) referring to becoming aware of where mistakes were made was 4.29. This was the highest mean obtained and indicates that students had the perception that they learned from their mistakes made when they wrote the individual assessments.

\section{Effect on performance}

Students agreed strongly that the assessment retake showed them how to do better in future, with a mean score of 4.17. They also agreed that it gave them an idea of how well they performed in relation to fellow students, with a mean of 4.08. From the comments it was clear that the opportunity to improve individual marks played a big role in the generally positive view of the assessment retake. Reinig et al. (2014) found that student satisfaction increased as more correct switches were made in team assessments, while also effectively improving their individual marks. With 18 students mentioning that the assessment retakes improved their marks, the reasons provided were mostly due to improved understanding and correction of mistakes by team members. Further research is however required to determine the effect of the group assessments on future performance of individual students, as higher marks in group assessment retakes do not necessarily lead to better future performance for individuals (Gabbin and Wood 2008).

\section{Improvement in understanding}

Even if there is uncertainty regarding the efficacy of cooperative learning to improve individual performance, group work that leads to improved understanding is still worthwhile (Bay and 
Pacharn 2017). On the two statements (5 and 6 in Table 1) addressing the improvement in understanding, the respective means were 3.88 and 3.83 , indicating a relatively strong agreement. From the response to the open-ended questions (b, $d$ and e) it was also clear that students perceived that explanations from peers played a big role in improving their understanding.

\section{Improvement in way of learning}

The method of feedback as part of broader formative assessment can have a significant effect on student learning (Watty et al. 2013). As far as improvement in individual learning is concerned, the mean response for the two applicable statements (number 7 and 8 in Table 1) were 3.71 and 3.75 respectively. These means still reflect a high level of agreement, but were the lowest means for the different aspects evaluated. To evaluate how much the students' approach to learning has changed as a result of an educational intervention can be a very subjective measurement. Although students perceived that their way of learning improved, future research may shed a different light on how students changed their approach to learning following the introduction of a two-stage group assessment.

\section{Student acceptance}

With 21 out of 24 students indicating that they would like to make use of assessment retakes in future, it is clear that the method was well received, as was the case in other studies on group assessments (Bay and Pacharn 2017). Apart from citing the opportunity to improve their marks, which provides a tangible and almost immediate benefit, most students cited improved understanding of the work as a result of the assessment retake. Improved understanding and corroboration with fellow students were also given as the main reason why students enjoyed the assessment retake. Many students indicated further that they enjoyed the interaction with group members and the opportunity to voice their own opinions. Only two students were negative, with one of them showing a preference to work on his/her own.

The biggest negative aspect mentioned by students was the issue of some members of the group not contributing but still receiving the benefit of improved marks due to the effort of the rest of the group. Joyce (1999) stated, "Perhaps, the existence of the free-rider problem is the biggest negative cost associated with cooperative learning”. Some researchers implemented a system where students rate each other's contribution to the team effort. This in itself is not without problems. Reinig et al. (2014) concluded that student evaluations in their study were too sporadic and mixed to reach meaningful conclusions through analysis.

Communication issues with fellow group members were also reported, one issue being 
the matter of different languages. All students could converse in English, but in one instance two Afrikaans first-language students refused to speak English, leaving the English-speaking student out of the discussion. Otherwise, instances of dominance by certain group members were reported, but in general students enjoyed the interaction with fellow students and being given the opportunity to voice their opinions.

\section{Gender}

In general, the means of female students' responses were higher than those of the male students. There was, however, only one statement (no 1 in Table 1) where the response showed a statistically significant difference, namely "Discussions during group tests helped me understand where I am making my mistakes", with a p-value of 0.04 .

Women generally seem to prefer cooperative learning more than men do (Opdecam et al. 2012). This appears to be the case also in this study. Given the small sample size the achievement of low p-values is less likely. Lower p-values could have resulted if there had been a larger sample size (Hahn and Ang 2017).

\section{CONCLUSION}

Cooperative learning was identified as a tool to improve the pervasive skill of accounting students of working effectively in a team (Bay and Pacharn 2017). This study investigated the potential of two-stage group assessments to improve the feedback process. The first stage of the evaluation involved students completing an assessment on an individual basis, followed by a second stage during which the same assessment was re-attempted in teams.

Students perceived that, in descending order, two-stage assessments helped them to identify mistakes they had made in their individual efforts; to gauge their relative performance and to improve future performance; and to understand the work better and to improve their learning. Students were very positive about the intervention and were in favour of broader use of the approach in future. While the issues of free riding and interpersonal friction endemic to team learning were also reported, students seemed generally to enjoy the interaction with fellow students and recognised the value that their peers added to their learning experience. This finding of students being generally satisfied is in line with other studies on team learning in accounting education (Reinig et al. 2014).

Based on the criteria for effective feedback according to Hattie and Timperley (2017), the information provided by their peers on their understanding and performance during the group examinations, assisted students to build on their initial learning when they prepared for the individual examinations. This study provides support for the effectiveness of the retake of an 
assessment, which involves cooperative learning, as a means to provide feedback to accounting students.

Although the group of students in this study was quite small, making the implementation easier, other researchers, such as Hite (1996), reported that the adoption of the group assessments was a relatively simple process for a bigger group of students. In this study, the fact that the students knew each other quite well and that they were already used to being actively engaged in class settings could have played a role in how well the two stage group assessment was accepted by students, compared to bigger groups used to conventional teaching approaches. Given the small sample size, the results of this study are only applicable to this group of students. Introducing this intervention to bigger groups and other subjects will provide better insight into the efficacy of assessment retakes as a method to improve student feedback.

\section{REFERENCE LIST}

Bargh, J. A. and Y. Schul. 1980. On the cognitive benefits of teaching. Journal of Educational Psychology 72(5): 593-604.

Bay, D. and P. Pacharn. 2017. Impact of group exams in a graduate intermediate accounting class. Accounting Education 26(4): 316-334

Biggs, J. 1999. What the student does. Higher Education Research \& Development 18(1): 57-75.

Blayney, P. and M. Freeman. 2008. Individualised interactive formative assessments to promote independent learning. Journal of Accounting Education 26(3): 155-165.

Clinton, B. D. and J. M. Kohlmeyer III. 2005. The effects of group quizzes on performance and motivation to learn: Two experiments in cooperative learning. Journal of Accounting Education 23: 96-116.

Coetzee, S. A., A. Schmulian and L. Kotze. 2014. Communication apprehension of South African accounting students: The effect of culture and language. Issues in Accounting Education 29(4): $505-525$.

Cortright, R. N., H. L. Collins, D. W. Rodenbaugh and S. E. DiCarlo. 2003. Student retention of course content is improved by collaborative-group testing. Advances in Physiology Education 27(3): $102-108$.

Cottell, P. G. and B. J. Millis. 1992. Cooperative learning in accounting. Journal of Accounting Education 10(1): 95-111.

Cross, M. and C. Carpentier. 2009. "New students" in South African higher education: Institutional culture, student performance and the challenge of democratisation. Perspectives in Education 27(1 March): 6-18.

Curtis, S. M. 2011. Formative assessment in accounting education and some initial evidence on its use for instructional sequencing. Journal of Accounting Education 29(4): 191-211.

De Lange, P. and K. Watty. 2011. Accounting education at a crossroad in 2010 and challenges facing accounting education in Australia. Accounting Education 20(6): 625-630.

Ellery, K. 2008. Assessment for learning: A case study using feedback effectively in an essay-style test. Assessment \& Evaluation in Higher Education 33(4): 421-429.

Evans, C. 2013. Making sense of assessment feedback in higher education. Review of Educational Research 83(1): 70-120.

Fluckiger, J., Y. Tixier, R. Pasco and K. Danielson. 2010. Formative feedback: Involving students as partners in assessment to enhance learning. College Teaching (58): 136-140. 
Gabbin, A. L. and L. I. Wood. 2008. An experimental study of accounting majors' academic achievement using cooperative learning groups. Issues in Accounting Education 23(3): 391-404.

Gibbs, G. and C. Simpson. 2005. Conditions under which assessment supports students' learning. Learning and Teaching in Higher Education 1: 3-31.

Gilbert, L., D. Whitelock and V. Gale. 2011. Synthesis report on assessment and feedback with technology enhancement. University of Southamton.

Guthrie, J., E. Evans and R. Burritt. 2014. Australian accounting academics: Challenges and possibilities. Meditari Accountancy Research 22(1), 20-37.

Guthrie, J., and Parker, L. D. 2014. The global accounting academic: What counts! Accounting, Auditing and Accountability Journal 27(1): 2-14.

Hahn, E. D. and S. H. Ang. 2017. From the editors: New directions in the reporting of statistical results in the Journal of World Business. Journal of World Business 52(2): 125-126.

Hattie, J. and H. Timperley. 2017. The power of feedback. Review of Educational Research 77(1): 81112.

Hesketh, J. 2011. Accounting academics' multiple challenges: Issues-driven learning offers a way forward. South African Journal of Accounting Research 25(1): 1-34.

Hite, P. A. 1996. An experimental study of the effectiveness of group exams in an individual income tax class. Issues in Accounting Education 11(1): 61-75.

Hounsell, D., V. Mccune, J. Hounsell and J. Litjens. 2008. The quality of guidance and feedback to students. Higher Education Research \& Development 27(March): 55-67.

Hwang, N. R., G. Lui, M. Yew and J. Wu. 2005. An empirical test of cooperative learning in a passive learning environment. Issues in Accounting Education 20 (May): 151-166.

Johnson, R. and A. Onwuegbuzie. 2004. Mixed methods research: A research paradigm whose time has come. Educational Researcher 33(7): 14-26.

Johnson, D. W., R. T. Johnson and K. A. Smith. 1991. Active leaming: Cooperation in the college classroom. Edina, MN: Interaction Book Company.

Joyce, W. B. 1999. On the free-rider problem in co-operative learning. Journal of Education for Business 74(5): 130-153.

Keevy, M. 2015. Using collaborative learning exercises to transfer pervasive skills: Some South African evidence. Journal of Economic and Financial Sciences 8(2): 456-473.

Lubbe, I. 2014. Educating professionals. Meditari Accountancy Research 22(1): 107-127.

Marriott, P. and L. K. Teoh. 2012. Using screencasts to enhance assessment feedback: Students' perceptions and preferences. Accounting Education 21(6): 583-598.

McCarthy, J. 2015. Evaluating written, audio and video feedback in higher education summative assessment tasks. Issues in Educational Research 25(2): 153-169.

Mungal, A. and M. Cloete. 2017. Preparing underprepared students for higher education and beyond: The development and implementation of an integrated project. Accounting Education 25(3): 203222.

Opdecam, E. and P. Everaert. 2012. Improving student satisfaction in a first-year undergraduate accounting course by team learning. Issues in Accounting Education 27(1): 53-82.

Opdecam, E., P. Everaert, H. Van Keer and F. Buysschaert. 2012. The effect of team learning on student profile and student performance in accounting education. Working Paper: Universiteit Gent.

Perera, L., H. O. A. Nguyen and K. I. M. Watty. 2014. Formative feedback through summative tutorialbased assessments: The relationship to student performance. Accounting Education 23(5): 424442.

Pitt, E. and L. Norton. 2017. "Now that's the feedback I want!" Students' reactions to feedback on graded work and what they do with it. Assessment \& Evaluation in Higher Education 42(4): 499516. 
Reinig, B. A., I. Horowitz and G. Whittenburg. 2014. Determinants of student attitudes toward team exams. Accounting Education 23(3): 244-257.

Roediger, H. L. and J. D. Karpicke. 2006. Test-enhanced learning: Taking memory tests improves longterm retention. Psychological Science 17(3): 249-255.

Rudman, R. and W. Kruger. 2014. Using a group work project as an educational tool in management accounting education. International Business \& Economics Research Journal 13(3): 611-628.

South African Institute of Chartered Accountants. 2016. Competency framework: Detailed guidance for the academic programme.

Samkin, G. and A. Schneider. 2014. The accounting academic. Meditari Accountancy Research 22(1): 2-19.

Shaw, M. E., B. Ackerman, N. E. McCown, A. P. Worsham, L. D. Haugh, B. M. Gebhardt and P. A. Small. 1979. Interaction patterns and facilitation of peer learning. Small Group Research 10(2): 214-223.

Shaw, M. E. and P. A. Small. 1981. Interaction patterns and facilitation of peer learning: Two replications. Small Group Research 12(2): 233-240.

Slavin, R. E. and N. L. Karweit. 1981. Cognitive and affective outcomes of an intensive student team learning experience. Journal of Experimental Education 50(1): 29-35.

Smit, S. and G. Steenkamp. 2015. The competencies developed in an undergraduate accounting course before SAICA's competency framework was effective: A student's perspective. Journal of Economic and Financial Sciences 8(2): 666-688.

SAICA see South African Institute of Chartered Accountants.

Stainbank, L. 2003. Using an annual report as a group project in accounting education. Meditari Accountancy Research 11: 151-166.

Stainbank, L. J. 2009. Working in teams: Improving the team experience. Meditari Accountancy Research 17(1): 69-80.

Strauss-Keevy, M. 2014. Education programmes' responsibilities regarding pervasive skills. Journal of Economic and Financial Sciences 7(2): 415-432.

Thondhlana, G. and D. Z. Belluigi. 2014. Group work as "terrains of learning" for students in South African higher education. Perspectives in Education 32(4): 40-56.

Thondhlana, G. and D. Z. Belluigi. 2016. Students' reception of peer assessment of group-work contributions: Problematics in terms of race and gender emerging from a South African case study. Assessment \& Evaluation in Higher Education 2938(September): 1-14.

Van Gennip, N. A. E., M. S. R. Segers and H. H. Tillema. 2009. Peer assessment for learning from a social perspective: The influence of interpersonal variables and structural features. Educational Research Review 4(1): 41-54.

Watty, K., P. de Lange, R. Carr, B. O'Connell, B. Howieson and B. Jacobsen. 2013. Accounting students' feedback on feedback in Australian universities: They're less than impressed. Accounting Education 22(5): 467-488.

Weaver, M. R. 2006. Do students value feedback? Student perceptions of tutors' written responses. Assessment \& Evaluation in Higher Education 31(3): 379-394.

Zipp, J. F. 2007. Learning by exams: The impact of two-stage cooperative tests. Teaching Sociology 35(January): 62-76. 